\title{
Matriz de impacto para gestão de microbacias com ótica na produtividade agropecuária sustentável e na saúde da população rural: Estudo de caso em quatro regiões da microbacia Rio do Colégio - São Fidélis - RJ
}

\author{
Matrix impact on watersheds management with optical sustainable agricultural productivity and \\ health of the rural population: A case study in four regions of the watershed Rio do Colégio - São \\ Fidelis $-R J$ \\ Salomão Brandi da Silva ${ }^{1}$, Cristina Aparecida Gomes Nassar ${ }^{2}$ \\ Instituto Federal Fluminense - Campus Centro \\ ${ }_{2}^{2}$ Universidade Federal do Rio de Janeiro
}

\section{Resumo}

O presente trabalho teve por objetivo avaliar a preservação dos recursos naturais da microbacia Rio do Colégio, bem como a saúde da população rural. A microbacia foi dividida em subáreas onde foram realizadas visitas, entrevistas e análise microbiológica da água. Foi elaborada uma matriz de impacto baseada na saúde populacional, saneamento rural e no uso dos recursos naturais. A matriz se mostrou eficaz na identificação dos principais impactos em cada região da microbacia. A maior incidência esgotamento sanitário peridomiciliar, foi constatada nas regiões de Santo Aleixo e Toca Fria. A falta de manejo com o gado foi um problema observado em todas as regiões analisadas, implicando num aumento significativo dos coliformes E. coli. Toda a população entrevistada consome água sem tratamento. Nas regiões da Toca Fria, Santo Aleixo e Aracaju a população se serve das nascentes livre da contaminação de esgotos domésticos, mas com acesso ao gado na maioria dos casos. Já na região do Rio do colégio algumas famílias utilizam das águas do curso principal. Altos índices de diarreias e verminoses coincidiram com as áreas de maior significância de impacto apontadas pela matriz. Foram apresentadas medidas mitigatórias de baixo custo econômico e de grande viabilidade para os impactos caracterizados.

Palavras-chave: Matriz de impacto; Indicadores de saúde; Saneamento básico rural; Saúde da população rural; Manejo na agropecuária.

\begin{abstract}
The present work aimed to evaluate the preservation of natural resources River College watershed as well as the health of the rural population. The watershed was divided into sub-areas which were visited, and interviews conducted microbiological analysis of water. An impact matrix based on population health, rural sanitation and the use of natural resources was created. The matrix was effective in identifying the main impacts in each region of the watershed. The highest incidence sewage peridomicilary, was found in the regions of Santo Aleixo and Toca Fria. Lack of management with cattle was a problem observed in all regions analyzed, resulting in a significant increase in E. coli coliform. All interviewed population consumes untreated water. In regions of the Toca Fria, Santo Aleixo and Aracaju the population makes use of free nascent of contamination from domestic sewage, but with access to cattle in most cases. In the Rio do Colégio region some families use water from the main course. High rates of diarrhea and worms coincide with the areas of greatest significance of impact indicated by the matrix. Mitigation measures were presented low economic cost and with high visibility to characterized impacts.
\end{abstract}

Keywords: Matrix impact; Indicators of health; Rural sanitation; Health rural population; Management in agriculture and livestock. 


\section{Introdução}

Um instrumento muito utilizado para planejamento e gestão ambiental em geral, são os indicadores ambientais, esses são úteis na identificação e previsão de impactos ambientais e no monitoramento da qualidade ambiental (SÁNCHEZ, 2013).

Segundo Heink e Kowaric (2010), os indicadores podem identificar e quantificar um fenômeno ambientalmente relevante, sendo possível avaliar as condições ou alterações ambientais, traçando metas ambientais.

Outra ferramenta comumente usada nos estudos ambientais são as matrizes de impacto, onde os elementos ambientais e as atividades do empreendimento se interconectam através de linhas e colunas, com o objetivo de identificar as interações do projeto com o ambiente (SÁNCHEZ, 2013). Leopold et al.(1971) e seus colaboradores foram pioneiros na elaboração e utilização das matrizes de impacto, propuseram uma matriz com cem ações antrópicas alistadas horizontalmente e 88 características ambientais na vertical, desta forma, pode-se observar 8800 interações, cada célula que compõe a integração ação/ambiente contém valores de 1 a 10 para expressar a magnitude(canto superior esquerdo) e a importância do impacto (canto inferior esquerdo).

Hoje em dia, há inúmeros modelos de matrizes, diferindo totalmente da matriz de Leopold (SÁNCHEZ, 2013), como exemplo, podemos citar as matrizes de ponderação elaborada por Rodrigues e Campanhola (2003) que tem sido amplamente empregado em estudos ambientais em zonas rurais, o sistema de Avaliação Ponderada de Impacto Ambiental de Atividades do Novo Rural (APOIA-Novo Rural), utiliza um conjunto de planilhas eletrônicas (plataforma MS-Excel), estruturado em 62 indicadores selecionados, que abrangem uma ampla gama de atividades agropecuárias, para a caracterização e gestão dos possíveis impactos ambientais, além da certificação de atividades agropecuárias.

Gracioli (2005) elaborou uma matriz de impacto baseado no modelo Leopold, para a avaliação da microbacia Vacacaí-Mirim em Santa Maria-RS. Para a avaliação da significância dos impactos, a autora atribuiu pesos aos indicadores propostos e apresentou um modelo matemático para a obtenção da magnitude e importância dos impactos.

Por outro lado encontramos na literatura a utilização de inúmeras matrizes mais simplificadas para estudos ambientais (SÁNCHEZ 2013).

Para o estudo das regiões da microbacia Rio do Colégio foi elaborada uma matriz que tem como diferencial a inserção indicadores que são amplamente utilizados na Engenharia Sanitária e Ambiental e na Engenharia de Saúde Pública (morbidades, internações, verminoses e doenças transmitidas por vetores). Desta forma busca-se relacionar as atividades desenvolvidas com morbidades específicas.

Portanto, a matriz apresentada nesse trabalho utiliza indicadores de morbidades advindas das práticas e condições rurais como: saneamento, manejo na agropecuária e supressão da vegetação. Essa forma de avaliação vem se consolidando como outra especialização de avaliação de impactos (SÁNCHEZ, 2013; ICMM, 2010).

As regiões da microbacia Rio do Colégio selecionada para estudo se encontram totalmente localizada no Município de São Fidélis - RJ. Atualmente se faz necessário analisar a qualidade dos recursos ambientais, pois os mesmos são utilizados pela população local para subsistência e para atividades econômicas tais como: agricultura, pecuária e piscicultura. Até o momento, não se conhece a existência de impactos ambientais e na saúde população, já que se trata de um trabalho pioneiro. Desta forma são necessários estudos para avaliar as reais condições socioambientais, assim como o manejo das atividades agropecuárias, apresentando propostas sustentáveis no caso da caracterização de impactos significativos. 


\section{Material e Métodos}

\section{1 Área de estudo}

A microbacia do Rio do Colégio localiza-se no município de São Fidélis, no Estado do Rio de Janeiro, entre as coordenadas $21^{\circ} 49^{\prime} \mathrm{S}, 41^{\circ} 55^{\prime} \mathrm{W}$; 21ํำ $51^{\prime} \mathrm{S}, 41^{\circ} 53^{\prime} \mathrm{W}$; $21^{\circ} 38^{\prime} \mathrm{S}, 41^{\circ} 39^{\prime} \mathrm{W}$ e $21^{\circ} 40^{\prime} \mathrm{S}, 41^{\circ} 38^{\prime}$, tendo como foz o rio Paraíba do Sul. A microbacia apresenta uma área com cerca de 20.000 ha. As regiões de Toca Fria e Santo Aleixo, Aracaju e Rio do Colégio foram delimitadas para estudo em função da densidade populacional e a Fazenda Recreio devido à extensa atividade pecuária exercida sem o manejo adequado (figura 1).

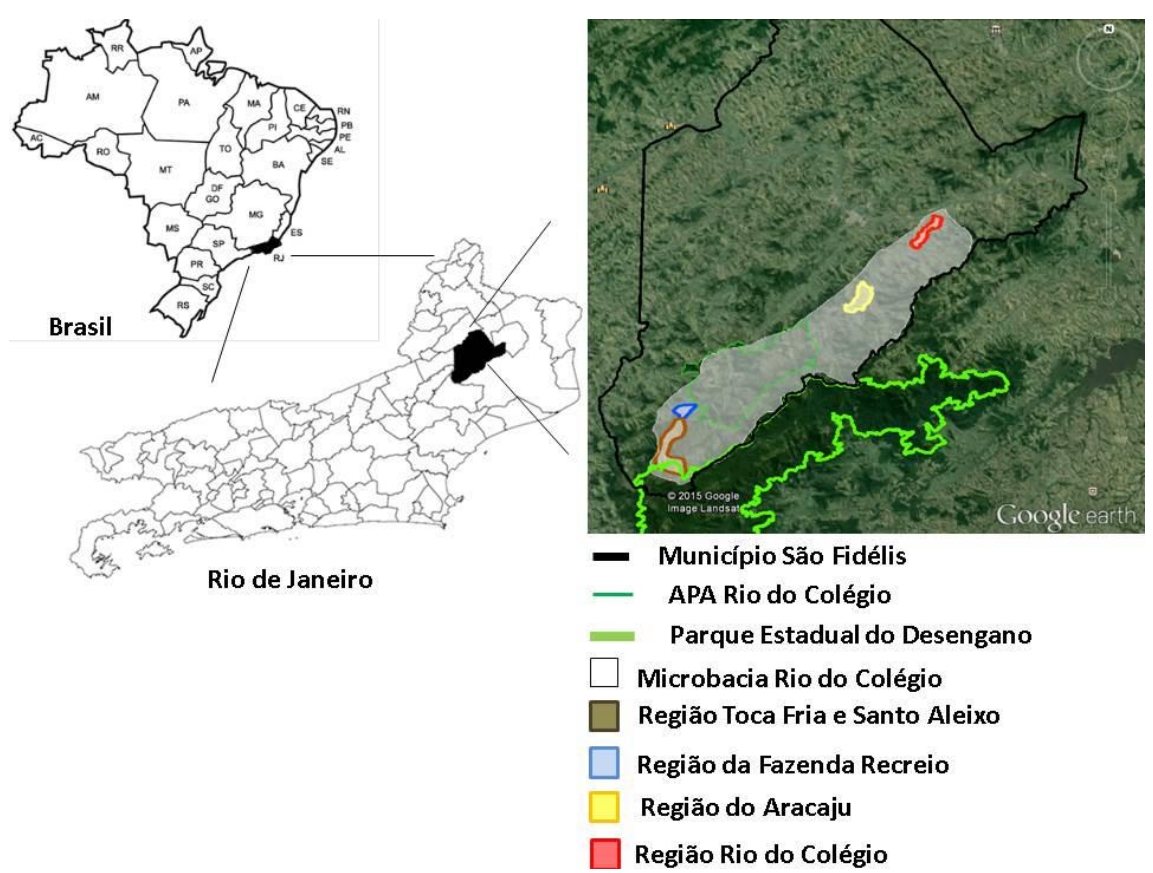

Figura 1 - Área territorial do Município de São Fidélis, com localização da microbacia Rio do Colégio e as regiões delimitadas para estudo. Fonte: IBGE; Google Earth Pro

\subsection{Pesquisa de campo}

Para a caracterização dos impactos socioambientais, foi elaborado um check list com os principais indicadores de impactos socioambientais negativos para zona rural, embasado em Palhares e Gebler (2014); Heller (1997); FUNASA (2010); Rodrigues e Campanhola (2003); Bockstaller et al., (2009). Os indicadores foram divididos em três eixos: Saneamento, Utilização dos recursos naturais e Saúde da população rural, conforme Figura 2.

A partir dos indicadores selecionados foram elaborados questionários utilizados na pesquisa de campo. No primeiro, foi avaliada a infraestrutura domiciliar e a utilização dos recursos naturais pelos moradores. Nessa etapa foi observado: o ponto de captação de água para consumo humano; a situação da nascente com relação à existência de mata ciliar e acesso de animais; forma de esgotamento sanitário e distância do curso hídrico mais próximo; atividades econômicas exercidas como agricultura e a utilização de agrotóxicos e adubo químico; a origem da água utilizada na pecuária, suinocultura, piscicultura e a proximidade dos dejetos com os cursos hídricos; além do destino dos resíduos sólidos domésticos.

No segundo questionário, foi verificada a incidência de sintomas que apontassem para Doenças Relacionadas ao Saneamento Ambiental Inadequado (DRSAI) (FUNASA, 2010). 


\subsection{Análise de dados}

Foi elaborada uma matriz de impacto, embasado no modelo de Leopold (LEOPOLD et al. 1971), onde os indicadores de cada eixo compuseram as colunas e os estabelecimentos de uma determinada área de estudo, formaram as linhas da matriz, desta forma, ao inserir os dados dos questionários aplicados, obteve-se a significância do impacto para esse imóvel ao final da linha. Através da média ponderada de todos os imóveis analisados na área de estudo obteve-se a significância do impacto para a região (figura $2 a \mathrm{e} 2 \mathrm{~b}$ ).

Além disso, a matriz conta com 40 indicadores bem definidos, cobrindo a maioria dos aspectos e impactos ambientais negativos para zona rural. A matriz foi inserida no editor de planilha da Microsoft Office Excel facilitando o manuseio e interpretação dos dados (figura 2a e 2b).

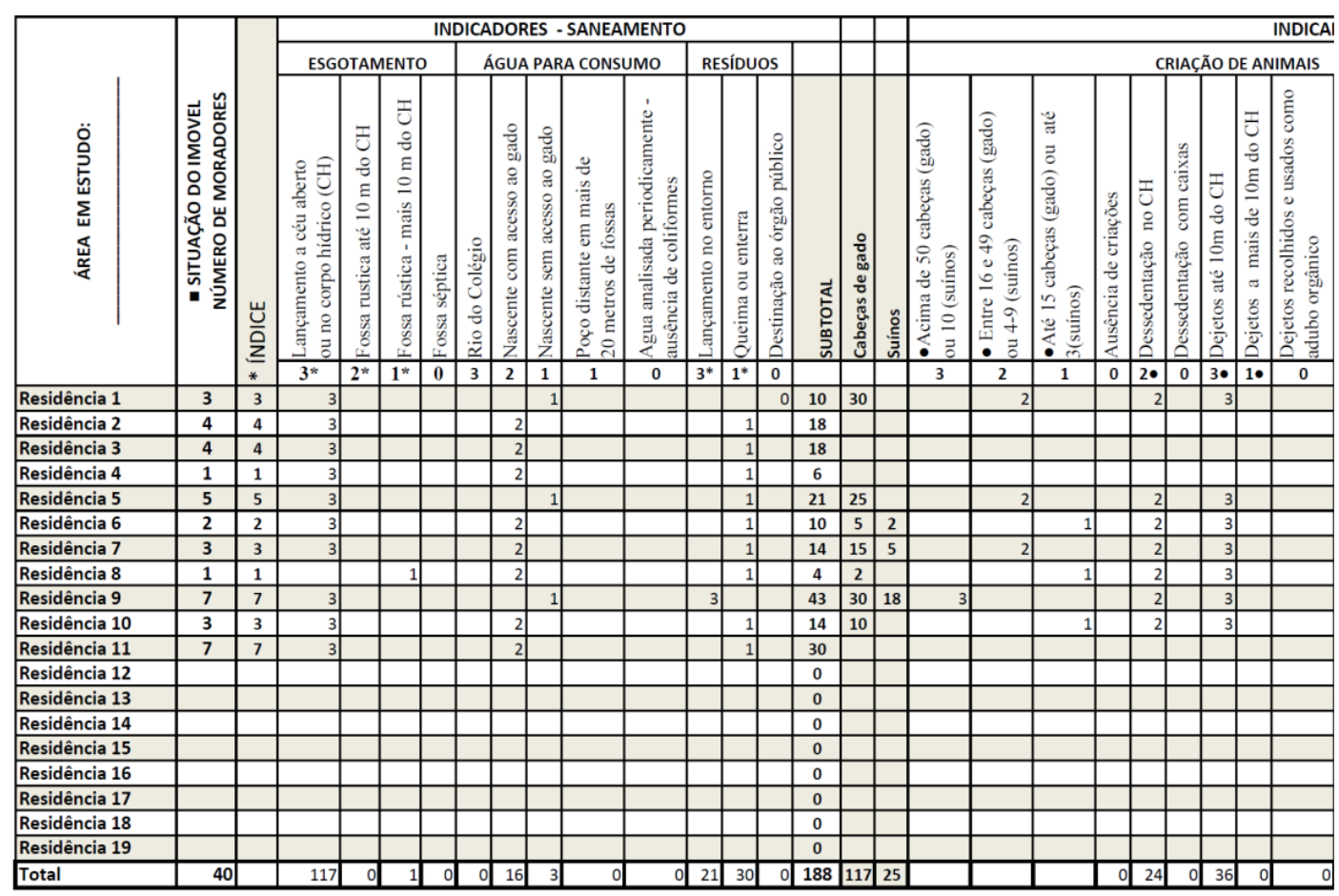

Figura 2a - Matriz de impacto elaborada com os dados das regiões da Toca Fria e Santo Aleixo

\begin{tabular}{|c|c|c|c|c|c|c|c|c|c|c|c|c|c|c|c|c|c|c|c|c|c|c|}
\hline \multicolumn{13}{|c|}{ DORES - UTILLZAÇC̄O DOS RECURSOS NATURAIS } & \multicolumn{10}{|c|}{ INDICADORES - SAÚDE } \\
\hline & & & & & AGRICI & ULTURA & & & & EGET: & Čุ̃̃o & & & RREA & & :RMIN & OSES/VEF & RMIFUG & & & & \\
\hline 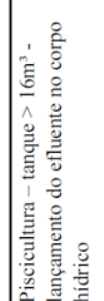 & 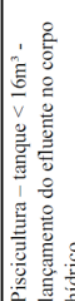 & 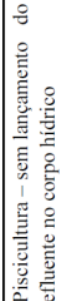 & 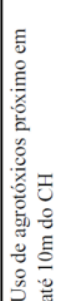 & 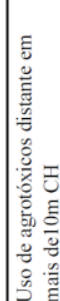 & $\mid$ & 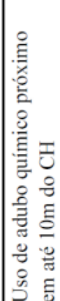 & 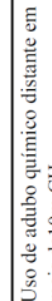 & & & 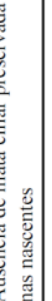 & 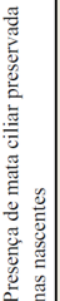 & t) & 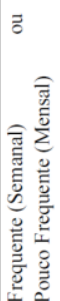 & 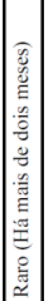 & 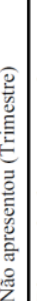 & 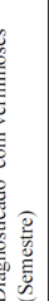 & 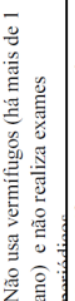 & 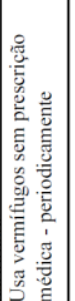 & 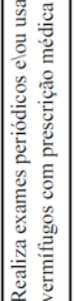 & & 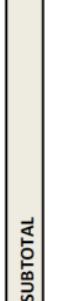 & 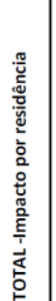 \\
\hline 2 & 1 & 0 & 2 & 1 & 0 & 2 & 1 & $=$ & & 2 & 0 & & $3^{*}$ & $1^{*}$ & 0 & $3^{*}$ & $2^{*}$ & $1^{*}$ & 0 & $3^{*}$ & 年 & 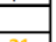 \\
\hline & & & & & & & & & & & & $\frac{11}{2}$ & & & & & & & & & $\mid \begin{array}{c}0 \\
15\end{array}$ & \\
\hline & & & & & & & & & & & & $\frac{2}{2}$ & & & & 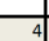 & & - & & & $\frac{15}{12}$ & $\frac{35}{32}$ \\
\hline & & & & & & & & & & & & 2 & & & & & & & & & 2 & \\
\hline & & & & & & & & & & & & $\frac{10}{7}$ & & & & & & $\underline{-5}$ & & & 10 & 41 \\
\hline & & & & & & & & & & & & 12 & & & & & & & & & 6 & 32 \\
\hline & & & & & & & & & & & & $\frac{7}{17}$ & & & & & & 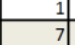 & & & $\frac{1}{7}$ & $\frac{12}{67}$ \\
\hline & & & & & & & & & & & & 7 & & & & & & & & & 7 & 28 \\
\hline & & & & & & & & & & & & $\frac{2}{8}$ & & & & & & & & & 27 & 59 \\
\hline & & & & & & & & & & & & 0 & & & & & & & & & 0 & \\
\hline & & & & & & & & & & & & $\frac{0}{0}$ & & & & & & & & & 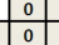 & \\
\hline & & & & & & & & & & & & 0 & & & & & & & & & 0 & \\
\hline & & & & & & & & & & & & $\frac{0}{0}$ & & & & & & & & & $\left|\begin{array}{l}0 \\
0\end{array}\right|-2-r \mid$ & \\
\hline & & & & & & & & & & & & 0 & & & & & & & & & & \\
\hline & & & & & & & & & & & & 79 & & & & & & & & & & \\
\hline
\end{tabular}


Figura $2 b$ - Continuação da matriz de impacto Significância do impacto para a região

Valores de 0 a 3 foram atribuídos aos indicadores de impactos negativos, sendo (0) para ausência ou impacto insignificante, (1) para impacto de baixa magnitude, (2) impacto magnitude média e (3) quando relacionado a impacto de grande magnitude. Essa atribuição baseou-se nos critérios apontados pelo Conama 1/86 art. 6 inciso II e Glasson et al. (2012), conforme tabela 1.

Tabela 1 - Atribuição de valores aos indicadores selecionados

\begin{tabular}{|c|c|c|c|c|c|c|c|c|}
\hline INDICADORES & 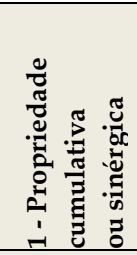 & 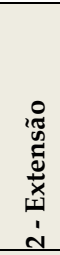 & 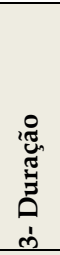 & 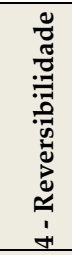 & 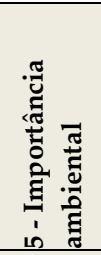 & 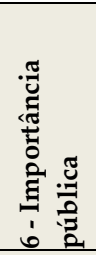 & 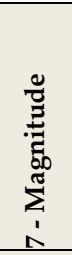 & 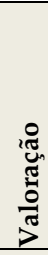 \\
\hline \multicolumn{9}{|l|}{ SANEAMENTO } \\
\hline Lançamento no corpo hídrico $(\mathrm{CH})$ ou a Céu aberto & A & $\mathrm{D}$ & $\mathrm{P}$ & RI & A & A & G & 3 \\
\hline Fossa rustica até $10 \mathrm{~m}$ do $\mathrm{CH}$ & M & $\mathrm{P}$ & $\mathrm{P}$ & RI & M & $\mathrm{B}$ & M & 2 \\
\hline Fossa rustica com mais $10 \mathrm{~m}$ do $\mathrm{CH}$ & $\mathrm{B}$ & $\mathrm{P}$ & $\mathrm{P}$ & $\mathrm{RN}$ & $\mathrm{B}$ & B & $\mathrm{B}$ & 1 \\
\hline Fossa séptica & * & * & * & * & * & * & I & 0 \\
\hline \multicolumn{9}{|l|}{ 2- Origem da água para consumo humano $(\mathrm{AH})$} \\
\hline Rio do Colégio ou afluentes & * & $P$ & $\mathrm{P}$ & RI & B & A & G & 3 \\
\hline Nascente com acesso ao gado & * & $\mathrm{P}$ & $\mathrm{P}$ & $\mathrm{RN}$ & B & M & M & 2 \\
\hline Nascente sem acesso ao gado & * & $\mathrm{P}$ & $\mathrm{P}$ & * & B & $\mathrm{B}$ & $\mathrm{B}$ & 1 \\
\hline Poço distante em mais de 20 metros de fossas & * & $\mathrm{P}$ & $\mathrm{P}$ & * & B & $\mathrm{B}$ & B & 1 \\
\hline Agua analisada periodicamente - ausência de coliformes & * & * & * & * & * & * & I & 0 \\
\hline \multicolumn{9}{|l|}{3 - Destinação do resíduo sólido (RS) } \\
\hline Lançamento no entorno & A & $\mathrm{D}$ & $\mathrm{P}$ & RI & A & A & G & 3 \\
\hline Queima ou enterra & $\mathrm{B}$ & $\mathrm{P}$ & $\mathrm{P}$ & $\mathrm{RN}$ & B & $\mathrm{B}$ & $\mathrm{B}$ & 1 \\
\hline Destinação ao órgão público & * & * & * & * & * & * & I & 0 \\
\hline \multicolumn{9}{|l|}{ UTILIZAÇÃO DOS RECURSOS NATURAIS } \\
\hline Dessedentação diretamente no $\mathrm{CH}$ & * & $\mathrm{D}$ & $\mathrm{P}$ & RI & B & A & M & 2 \\
\hline Dessedentação com caixas & * & * & * & * & * & * & I & 0 \\
\hline Dejetos próximos em até $10 \mathrm{~m}$ do $\mathrm{CH}$ & $\mathrm{S}$ & $\mathrm{D}$ & $\mathrm{P}$ & RI & B & A & M & 2 \\
\hline Dejetos distantes em mais de $10 \mathrm{~m}$ do $\mathrm{CH}$ & $\mathrm{S}$ & $\mathrm{P}$ & $\mathrm{P}$ & RI & B & $\mathrm{M}$ & $\mathrm{B}$ & 1 \\
\hline Dejetos recolhidos e usados como adubo orgânico & $\mathrm{B}$ & $\mathrm{P}$ & $\mathrm{T}$ & $\mathrm{RN}$ & B & $\mathrm{B}$ & I & 0 \\
\hline Piscicultura - tanque com lançamento do efluente no corpo hídrico & M & $\mathrm{D}$ & $\mathrm{P}$ & RI & B & $\mathrm{B}$ & M & 2 \\
\hline Piscicultura - sem lançamento do efluente no corpo hídrico & B & $\mathrm{P}$ & $\mathrm{P}$ & RN & B & $\mathrm{B}$ & I & 0 \\
\hline \multicolumn{9}{|l|}{ 2- Agricultura - comercial (AC) } \\
\hline Uso de agrotóxicos próximo em até $10 \mathrm{~m}$ do $\mathrm{CH}$ & A & $\mathrm{D}$ & $\mathrm{T}$ & $\mathrm{RN}$ & M & A & M & 2 \\
\hline Uso de agrotóxicos distante em mais de $10 \mathrm{~m} \mathrm{CH}$ & B & $\mathrm{P}$ & $\mathrm{T}$ & RN & M & M & $\mathrm{B}$ & 1 \\
\hline Não utilização & * & * & * & * & * & * & I & 0 \\
\hline Uso de adubo químico próximo em até $10 \mathrm{~m}$ do $\mathrm{CH}$ & A & $\mathrm{D}$ & $\mathrm{T}$ & RN & M & A & M & 2 \\
\hline Uso de adubo químico distante em mais de $10 \mathrm{~m} \mathrm{CH}$ & $\mathrm{B}$ & $\mathrm{P}$ & $\mathrm{T}$ & $\mathrm{RN}$ & M & M & $\mathrm{B}$ & 1 \\
\hline Uso de adubo orgânico & B & $\mathrm{P}$ & $\mathrm{T}$ & RN & M & $\mathrm{B}$ & I & 0 \\
\hline \multicolumn{9}{|l|}{ 3- Supressão da mata ciliar (SM) } \\
\hline Ausência de mata ciliar preservada nas nascentes & * & $\mathrm{P}$ & $\mathrm{T}$ & $\mathrm{RN}$ & M & M & M & 2 \\
\hline Presença de mata ciliar preservada nas nascentes & * & * & * & * & * & * & I & 0 \\
\hline \multicolumn{9}{|l|}{$\begin{array}{l}\text { SAÚDE DA POPULAÇÃO RURAL } \\
\text { 1- Morbidades (M)\Vermífugos (V) }\end{array}$} \\
\hline Diarreia \Cólica intestinal - Frequente (F) ou Pouco Frequente (PF) & - & - & $\mathrm{T}$ & - & A & A & G & 3 \\
\hline Diarreia \Cólica intestinal - Raro (R) & - & - & $\mathrm{T}$ & - & $\mathrm{B}$ & A & $\mathrm{B}$ & 1 \\
\hline Não apresentou & * & * & * & * & * & * & $\mathrm{I}$ & 0 \\
\hline Foi diagnosticado nos últimos 6 meses com verminoses & - & - & - & RI & A & A & G & 3 \\
\hline $\begin{array}{l}\text { Não usa vermífugos (há mais de } 1 \text { ano) e não realiza exames } \\
\text { periódicos }\end{array}$ & . & - & - & - & $\mathrm{M}$ & A & M & 2 \\
\hline Usa vermífugos sem prescrição médica - periodicamente & * & * & * & * & B & $\mathrm{M}$ & B & 1 \\
\hline $\begin{array}{l}\text { Realiza exames periódicos e } \backslash \text { ou usa vermífugos com prescrição } \\
\text { médica }\end{array}$ & * & * & * & * & * & $*$ & I & 0 \\
\hline
\end{tabular}




\begin{tabular}{lllllllllll} 
Outras patologias de DRSAI (OP) & - & - & - & A & A & A & 3 \\
\hline${ }^{*}$ Não se aplica & - Dependente de outros fatores
\end{tabular}

1 - Propriedade cumulativa ou sinérgica

2 - Extensão

3- Duração

4 - Reversibilidade

5 - Importância ambiental

6 - Importância pública

7 - Magnitude

Valoração

\author{
Alta (A), Média (M), Baixa (B) \\ Pontual (P) ou Difusa (D) \\ Temporário (T) ou Permanente (P) \\ Reversível naturalmente (RN), Reversível com intervenção (RI) ou Irreversível (I) \\ Alta (A), Média (M) ou Baixa (B) \\ Alta (A), Média (M) ou Baixa (B) \\ Grande (G), Média (M) ,Baixa (B) ou Insignificante (I) \\ Grande $=3$, Média $=2$ Baixa $=1$ ou Insignificante $=0$
}

A partir da pesquisa com os moradores da zona rural foram obtidos dados sobre uma família típica para a localidade, que possua medidas mitigadoras mínimas. As características encontradas apontam para uma família composta por três a quatro pessoas, que consuma água de uma nascente preservada, sem acesso ao gado, possua fossa rústica distante em mais de 20 metros do corpo hídrico ou poços, queime parte dos resíduos domésticos, tenha cerca de 20 cabeças de gado (para subsistência) com dessedentação em caixas e que permaneçam distantes em mais de 10 metros do corpo hídrico, possua um tanque de peixe e não lance o efluente diretamente nos recursos hídricos, que não relate apresentar sintomas de diarreias ou cólicas abdominais ou quaisquer outras DRSAI e utilize vermífugos sem prescrição médica.

Desta forma foram dimensionados índices para o quantitativo de animais, onde até 15 cabeças de gado ou até 03 suínos adotou-se o índice de criações (IC) igual a (1). De 16 a 50 cabeças de gado ou de 4 a 10 suínos, IC (2) e acima desses quantitativos, IC (3). O quantitativo menor de suínos adotado em relação aos bovinos se deve ao sistema empregado de confinamento em proximidade aos corpos hídricos, exigindo que os dejetos sejam tratados, evitando contaminação contínua dos cursos hídricos, disseminações de doenças e maus odores (PALHARES e GEBLER, 2014), o que normalmente não ocorre. No entanto, o quantitativo não é o grande problema das criações de animais, a implicação maior está relacionada em como exercer a atividade produtiva impactando menos o ambiente, ou seja, com o manejo sustentável.

O fator multiplicador (FM) usado no cálculo está relacionado ao número de moradores, já que a contribuição de lodo fresco produzido é diretamente proporcional ao número de pessoas (JORDÃO e PESSOA, 2009), assim como a quantidade de resíduos sólidos domésticos gerados. No caso de residências de passeio ou igrejas o índice adotado foi (1) e para mercearias e bares índice (3), com base no número de pessoas que frequentam os estabelecimentos (NBR 7229).

A significância do impacto por residência foi obtida a partir do somatório dos indicadores de saneamento, utilização dos recursos naturais e saúde, conforme o cálculo verificado em (1):

Onde:

$$
\begin{aligned}
& \mathbf{S I R}=((\mathrm{ES}+\mathrm{RS}) * \mathrm{FM}+\mathrm{AH})+\left(\mathrm{IC}^{*} \mathrm{DA}+\mathrm{IC} * \mathrm{DD}+\mathrm{P}+\mathrm{AC}+\mathrm{SM}\right)+(\mathrm{M} * \mathrm{~Np}+\mathrm{V} * \mathrm{~Np}+\mathrm{OP} * \mathrm{~Np}) \\
& \text { Saneamento Utilização dos recursos naturais Saúde da população }
\end{aligned}
$$

SIR = Significância do impacto residencial

ES= Esgotamento sanitário

$\mathrm{AH}=$ Água para consumo humano

$\mathrm{DD}=$ Distâncias dos dejetos

SM= Supressão da mata ciliar

$\mathrm{V}=$ Verminoses

$\begin{array}{ll}\text { RS }=\text { Resíduo sólido } & \mathrm{FM}=\text { Fator multiplicador } \\ \mathrm{IC}=\text { Índice de criações } & \mathrm{DA}=\text { Dessedentação animal } \\ \mathrm{P}=\text { Piscicultura } & \mathrm{AC}=\text { Agricultura comercial } \\ \mathrm{M}=\text { Morbidades } & \mathrm{Np}=\text { Número de pessoas } \\ \mathrm{OP}=\text { Outras patologias } & \end{array}$

RS= Resíduo sólido

$\mathrm{M}=$ Morbidades
$\mathrm{OP}=$ Outras patologias
FM= Fator multiplicador

$\mathrm{AC}=$ Agricultura comercial

$\mathrm{Np}=$ Número de pessoas

Uma família com três pessoas apresentará uma variação de 0 a 66 . Uma família típica da zona rural, conforme descrita anteriormente, que utilize os recursos naturais, tendo alguns procedimentos mitigadores mínimos, apresentaria uma significância de impacto avaliado em 12,0 . Portanto os valores obtidos para os imóveis analisados ou através da média ponderada para região, quando situados entre 
0-15 foram considerados como pouco significativo, valores entre 16-25 como moderado e acima de 25 crítico. Desta forma foi possível mensurar a significância dos impactos por residência e por região.

\subsection{Análise da água}

Foi realizada a análise microbiológica da água, a fim de confrontar os resultados obtidos pela matriz, com os índices de coliformes constatados. Durante a pesquisa de campo, pontos específicos (georreferenciados), foram estabelecidos os locais para a coleta, conforme figura 3. As coletas foram realizadas no período de estiagem em (12/11/2014) e repetidas nos mesmos pontos no início do período chuvoso (16/03/2015). As amostras foram acondicionadas em caixas térmicas com placas de gel congeladas e encaminhadas em menos de seis horas a Unidade de Pesquisa e Extensão AgroAmbiental (Upea - IFF), em Campos dos Goytacazes-RJ, para análise microbiológica.

Para análise dos coliformes totais e de termotolerantes da espécie E. coli foi misturado o Reagente Colilert IDEXX às amostras e homogeneizado. Em seguida transferido para a Cartela de cultura e selado pelo equipamento Quant-Tray Sealer.

As cartelas seguiram para a Estufa Ethik, onde permaneceram por $24 \mathrm{hrs}$ a $35^{\circ} \mathrm{C}$. Para leitura dos resultados, as cartelas foram inseridas no Leitor UV Boitton e analisadas as cavidades fluorescentes. As cavidades incolores indicaram ausência de coliformes, cavidades amarelas a presença de coliformes totais e as cavidades amarela-fluorescentes a presença de coliformes termotolerantes $(E$. coli).

Para quantificar o número de coliformes (Número Mais Provável - NMP) foi usada a Tabela de conversão do fabricante. O número de cavidades grandes é lido na vertical da tabela e o número das cavidades pequenas lido na horizontal. O resultado é dado no ponto de encontro dos dois valores encontrados na tabela em NMP.

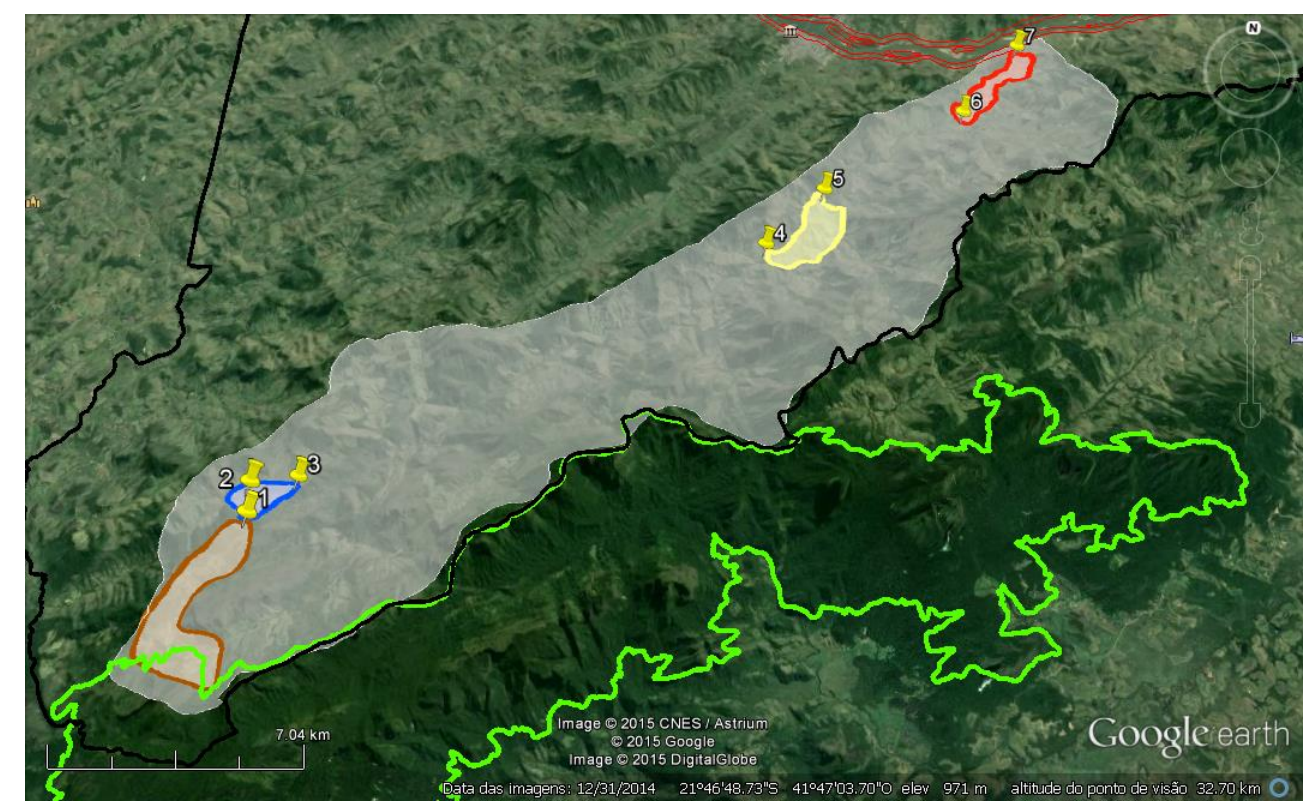

Figura 3 - Pontos estabelecidos para as coletas de água nas regiões da microbacia Rio do Colégio, no município de São Fidélis Fonte: Google Earth Pro

A Tabela 2 apresenta as coordenadas geográficas dos pontos de coleta e sua relação com as áreas analisadas. 
Tabela 2 - Referencial geográfico dos pontos estabelecidos para coleta

\begin{tabular}{ccccccc}
\hline Pontos & \multicolumn{2}{c}{$\begin{array}{c}\text { Coordenadas geográficas } \\
\text { Latitude }\end{array}$} & $\begin{array}{c}\text { Toca Fria e } \\
\text { Lanto } \\
\text { Aleixo }\end{array}$ & $\begin{array}{c}\text { Fazenda } \\
\text { Recreio }\end{array}$ & Aracaju & $\begin{array}{c}\text { Rio do } \\
\text { Colégio }\end{array}$ \\
\hline 1 & $21^{\circ} 49^{\prime} 21.2^{\prime \prime} \mathrm{S}$ & $41^{\circ} 53^{\prime} 46.0^{\prime \prime} \mathrm{O}$ & Jusante & & & \\
2 & $21^{\circ} 48^{\prime} 39.3^{\prime \prime S}$ & $41^{\circ} 54^{\prime} 00.6^{\prime \prime O}$ & & Montante & & \\
3 & $21^{\circ} 48^{\prime} 29.5^{\prime \prime} \mathrm{S}$ & $41^{\circ} 53^{\prime} 12.9^{\prime \prime} \mathrm{O}$ & & Jusante & & \\
4 & $21^{\circ} 43^{\prime} 34.6^{\prime \prime} \mathrm{S}$ & $41^{\circ} 45^{\prime} 26.2^{\prime \prime} \mathrm{O}$ & & & Montante & \\
5 & $21^{\circ} 42^{\prime} 24.2^{\prime \prime S}$ & $41^{\circ} 44^{\prime} 21.9^{\prime \prime O}$ & & & Jusante & \\
6 & $21^{\circ} 40^{\prime} 34.3^{\prime \prime} \mathrm{S}$ & $41^{\circ} 41^{\prime} 39.6^{\prime \prime O}$ & & & & Montante \\
7 & $21^{\circ} 39^{\prime} 01.8^{\prime \prime} \mathrm{S}$ & $41^{\circ} 40^{\prime} 32.6^{\prime \prime} \mathrm{O}$ & & & & Jusante \\
\hline
\end{tabular}

\section{Resultados e Discussão}

Através da pesquisa de campo foi possível analisar a infraestrutura 47 imóveis e realizar a pesquisa sobre saúde pública com 92 pessoas. Esses dados são bastante representativos, já que a estimativa da população da microbacia Rio do Colégio é de aproximadamente 300 (informações obtidas com a Secretaria de Desenvolvimento e Meio Ambiente de São Fidélis). A distribuição das residências analisadas, o número de pessoas entrevistadas por região, assim como o quantitativo de criações se encontra na tabela 3.

Tabela 3- Distribuição das residências analisadas, o número de pessoas entrevistadas por região da microbacia Rio do Colégio, assim como o quantitativo de criações

\begin{tabular}{lccccc}
\hline Áreas da microbacia & $\begin{array}{c}\text { Número de } \\
\text { residências }\end{array}$ & $\begin{array}{c}\text { Número de } \\
\text { moradores }\end{array}$ & Gado & Suíno & Piscicultura \\
\hline Toca Fria e Santo Aleixo & 11 & 40 & 117 & 25 & 3 \\
Fazenda Recreio & - & - & 700 & & \\
Aracaju & 20 & 16 & 100 & & 1 \\
Rio do Colégio & 16 & 36 & 90 & 2 & \\
\hline
\end{tabular}

Os dados obtidos na pesquisa de campo foram inseridos na matriz de impacto utilizando o software Excel. A Tabela 4 apresenta os valores para cada indicador analisado, com o respectivo percentual. Foram removidos os indicadores que não apontavam para um impacto ambiental negativo como: utilização de fossas sépticas, consumo de água tratada, destinação de resíduos sólidos aos órgãos públicos, presença de mata ciliar preservada nas nascentes, etc. Os indicadores de agricultura comercial também foram excluídos dos resultados já que não foram encontradas atividades agrícolas nas regiões analisadas.

Através da Tabela 3 é possível observar os principais problemas para cada região. Na Toca Fria e Santo Aleixo o esgotamento sanitário diretamente nos cursos hídricos ou a céu aberto nos arredores do domicílio e os índices de morbidades por diarreias e verminoses foram os mais preocupantes. A significância do impacto ambiental, obtida através da média ponderada das residências analisadas foi de 32,5 classificado como impacto crítico para essas regiões. A região do Aracaju demonstrou utilizar algumas medidas mitigadoras como a utilização de fossas rústicas e destinação dos resíduos sólidos aos órgãos públicos, sendo a falta de manejo na pecuária o maior problema encontrado. A significância do impacto para a região foi de 8,6 classificado como impacto pouco significativo. Na região do Rio do Colégio a significância do impacto foi de 13,4 próximo ao limite de impacto moderado. Os principais problemas observados foram à instalação de fossas rústicas próximas aos cursos hídricos, utilização das águas do curso hídrico principal para abastecer as residências e a destinação incorreta dos resíduos sólidos, mesmo havendo o serviço de coleta pública nessa região. Na região Fazenda Recreio foi encontrada apenas uma residência. A significância do impacto foi de 17, obtida observando apenas um dos eixos 
(Utilização dos Recursos Naturais). A seguir será discutido o resultado de cada indicador apontando as medidas mitigadoras de baixo custo e boa efetividade. Em seguida será abordado o resultado das análises da água.

Tabela 4 - Valores e percentuais dos indicadores utilizando a matriz de impacto para cada região analisada da microbacia do Rio do Colégio

\begin{tabular}{|c|c|c|c|}
\hline INDICADORES & $\begin{array}{c}\text { Toca Fria e } \\
\text { Santo Aleixo }\end{array}$ & Aracaju & $\begin{array}{l}\text { Rio do } \\
\text { Colégio }\end{array}$ \\
\hline \multicolumn{4}{|l|}{ SANEAMENTO } \\
\hline Lançamento no corpo hídrico $(\mathrm{CH})$ ou a Céu aberto & $117(33,0 \%)$ & $3(2,2 \%)$ & $3(1,4 \%)$ \\
\hline Fossa rustica até $10 \mathrm{~m}$ do $\mathrm{CH}$ & & $2(1,4 \%)$ & $26(12,1 \%)$ \\
\hline Fossa rustica com mais $10 \mathrm{~m}$ do $\mathrm{CH}$ & $1(0,3 \%)$ & $22(15,8 \%)$ & $26(12,1 \%)$ \\
\hline \multicolumn{4}{|l|}{ 2- Origem da água para consumo humano $(\mathrm{AH})$} \\
\hline Rio do Colégio ou afluentes & & & $30(14,0 \%)$ \\
\hline Nascente com acesso ao gado & $16(4,5 \%)$ & $12(8,6 \%)$ & $6(2,8 \%)$ \\
\hline Nascente sem acesso ao gado & $3(0,8 \%)$ & $24(17,3 \%)$ & \\
\hline Poço distante em mais de 20 metros de fossas & & & $3(1,4 \%)$ \\
\hline \multicolumn{4}{|l|}{3 - Destinação do resíduo sólido (RS) } \\
\hline Lançamento no entorno & $21(5,9 \%)$ & & \\
\hline Queima ou enterra & $30(8,5 \%)$ & $2(1,4 \%)$ & $21(9,8 \%)$ \\
\hline \multicolumn{4}{|l|}{$\begin{array}{l}\text { UTILIZAÇÃO DOS RECURSOS NATURAIS } \\
\text { 1- Criações de animais (IC) }\end{array}$} \\
\hline Dessedentação diretamente no $\mathrm{CH}$ & $24(6,8 \%)$ & $10(7,2 \%)$ & $10(4,7 \%)$ \\
\hline Dejetos próximos em até $10 \mathrm{~m}$ do $\mathrm{CH}$ & $36(10,1 \%)$ & $15(10,8 \%)$ & $15(7,0 \%)$ \\
\hline Dejetos distantes em mais de $10 \mathrm{~m}$ do $\mathrm{CH}$ & & & $3(1,4 \%)$ \\
\hline $\begin{array}{l}\text { Piscicultura - tanque com lançamento do efluente no corpo } \\
\text { hídrico }\end{array}$ & $6(1,7 \%)$ & $2(1,4 \%)$ & \\
\hline \multicolumn{4}{|l|}{ 3- Supressão da mata ciliar (SM) } \\
\hline Ausência de mata ciliar preservada nas nascentes & $14(3,9 \%)$ & $18(12,9 \%)$ & $6(2,8 \%)$ \\
\hline \multicolumn{4}{|l|}{$\begin{array}{l}\text { SAÚDE DA POPULAÇÃO RURAL } \\
\text { 1- Morbidades (M)\Vermífugos (V) }\end{array}$} \\
\hline $\begin{array}{l}\text { Diarreia \Cólica intestinal - Frequente }(\mathrm{F}) \text { ou Pouco } \\
\text { Frequente (PF) }\end{array}$ & $9(2,5 \%)$ & & $9(4,2 \%)$ \\
\hline Diarreia \Cólica intestinal - Raro (R) & $7(2,0 \%)$ & $2(1,4 \%)$ & $5(2,3 \%)$ \\
\hline Foi diagnosticado nos últimos 6 meses com verminoses & $33(9,3 \%)$ & & \\
\hline $\begin{array}{l}\text { Não usa vermífugos (há mais de } 1 \text { ano) e não realiza } \\
\text { exames periódicos }\end{array}$ & $22(6,2 \%)$ & $18(12,9 \%)$ & $10(4,7 \%)$ \\
\hline Usa vermífugos sem prescrição médica - periodicamente & $13(3,7 \%)$ & $6(4,3 \%)$ & $23(10,7 \%)$ \\
\hline 2- Outras patologias de DRSAI (OP) & $3(0,8 \%)$ & $3(2,2 \%)$ & $18(8,4 \%)$ \\
\hline
\end{tabular}

\subsection{Esgotamento sanitário}

Na região de Toca Fria e Santo Aleixo 91\% das residências possuem esgotamento diretamente nos cursos hídricos ou a céu aberto (com defecação em área aberta ou com canalização que escoa nas proximidades da residência), esse indicador foi responsável por 33\% da significância dos impactos para a região. Além disso, essas regiões estão localizadas na vertente da microbacia influenciando diretamente os usos da água para a população ou atividades econômicas a jusante. Com relação às regiões do Aracaju e Rio do Colégio apenas um imóvel em cada região pratica essa forma de esgotamento, no entanto, as instalações de fossas rústicas em proximidade ao corpo hídrico na região do Rio do Colégio correspondeu a 12,1\% da significância dos impactos para a região.

No Brasil houve melhorias significativas no setor de saneamento sanitário elevando o percentual populacional com esgotamento sanitário ideal de $67 \%$ para $81 \%$ entre 1990 e 2012 e uma redução de $17 \%$ para $3 \%$ para defecção a céu aberto. Nas áreas rurais, no entanto, ainda 17\% 
da população praticam defecação a céu aberto, apesar da enorme redução de $48 \%$ para $17 \%$ entre 1990 e 2012, OMS/UNICEF (2014). O Instituto Brasileiro relata que do ano 2000 para 2008 houve um aumento de $33,5 \%$ para $44 \%$ de residências que possuíam sistema de canalização dos esgotos (IBGE, 2008). Esse estudo não informou o percentual de pessoas que utilizam outras formas de esgotamento.

Segundo a OMS/UNICEF (2014) apesar dos avanços mundiais em promover um esgotamento sanitário adequado, ainda existem 2,5 bilhões de pessoas que não possuem instalações sanitárias apropriadas, sendo que $40 \%$ da população mundial (um bilhão de pessoas) ainda praticam a defecação a céu aberto, disseminando doenças, desnutrição e mortes prematuras.

O esgotamento sanitário inapropriado sobre o solo permite a proliferação de vetores para inúmeras doenças, transmissão de verminoses e contaminação de pastagens (JORDÃO e PESSOA, 2009), completando o ciclo de muitos helmintos.

Pinto et al. (2012) acrescenta que o esgotamento sanitário inapropriado em comunidades rurais, gera um grave problema de saúde devido ao grande número de patógenos eliminados no ambiente, além da ausência de quaisquer processos de tratamento, tornando os recursos hídricos, fontes potenciais de transmissão de doenças.

Heller e Pádua (2006) mencionam que os micro-organismos do gênero Cryptosporidium e Giardia, apresentam resistência a desinfecção, sendo de difícil remoção, mesmo em estações de tratamento e que técnicas para a sua identificação ainda não se encontram bem definidas, desta forma, o lançamento de dejetos humanos e animais comprometem a qualidade da água mesmo após tratamento, oferecendo riscos a saúde.

\subsubsection{Medidas mitigadoras}

Uma das estratégias empregadas a mais um século são as fossas sépticas. Nas fossas os dejetos são armazenados em uma ou várias câmaras por um período pré-determinado, onde ocorre a sedimentação do lodo e a retenção do material graxo, permitindo a digestão da matéria orgânica em compostos mais simples e a destruição de organismos patogênicos. A eficiência das fossas sépticas pode atingir 50\% na redução da matéria orgânica e $30 \%$ da DBO, no entanto, fica evidente a necessidade de manutenção periódica para o seu bom funcionamento (JORDÃO e PESSOA, 2009). A NBR $7229 / 93$ fornece informações para a construção e operação do sistema de fossas sépticas em câmara única e em série.

\section{2. Água para consumo humano}

No presente trabalho foi possível constatar que não existe nenhuma forma de tratamento da água e nem mesmo o fornecimento de caminhões pipas ou treinamento de pessoal para tratamento básico local para desinfecção por parte dos órgãos públicos, toda a população utiliza a água in natura. Os moradores, sempre que possível, procuram uma nascente distante em cerca de $500 \mathrm{~m}$, no entanto, a maior parte dessas nascentes não está preservada e permite o acesso de criações (Tabela 3). Também foi possível constatar moradores, da região do Rio do Colégio, utilizando água diretamente do curso hídrico principal o Rio do Colégio, já que as nascentes utilizadas anteriormente secaram.

Essas informações são preocupantes, já que não se conhece a qualidade dessas águas e existe um grande risco de veiculação hídrica de doenças. Segundo Prüss-Üstün (2008), cerca de $10 \%$ do total das doenças globais poderiam ser prevenidas com melhorias no saneamento básico e na gestão dos recursos hídricos.

Segundo Palhares (2010), o Brasil apresenta uma das piores situações na questão de saneamento e água potável no meio rural, comparado a outros países latino-americanos, portanto, é de suma importância políticas voltadas para o saneamento rural. 


\subsubsection{Medidas mitigadoras}

Vários métodos de tratamento da água estão disponíveis a baixo custo e de boa eficiência na redução das morbidades causadas por diarreias, dentre elas a desinfecção por radiação Ultravioleta (UV), fervura, filtração e cloração (ANA, 2011).

A fervura da água nem sempre é bem vista pela população, por apresentar sabor (relatos dos moradores da microbacia) ao ocorrer à liberação dos gases dissolvidos na água, durante o processo.

Com relação à radiação solar, segundo Heller e Pádua (2006) a maioria dos organismos patogênicos é eliminada ao ficar em contato com o calor e a radiação UV solar por cerca de 95minutos.

Outro método de tratamento individual bastante empregado é o uso de cloro e seus derivados, como: hipoclorito de sódio20 a 30\% de Cloro (líquido); água sanitária a 2\%; cloro granulado (pó) a 65\%; hipoclorito de cálcio (pó) a 10\%; cloro estabilizado em pastilhas (65 a 90\% de cloro). A dosagem do cloro varia conforme o produto utilizado, sempre obtendo a concentração de $1 \mathrm{mg} / \mathrm{L}$. O produto mais comercializado em função do custo, disponibilidade e facilidade é o hipoclorito de sódio (líquido) que possui de 2 a 2,5\% de cloro ativo, popularmente conhecido como água sanitária, no entanto, mesmo tratando de um processo simples e barato, exige cautela para se evitar erros na concentração utilizada (OTÊNIO et al., 2010).

Além das medidas mencionadas, os órgãos ambientais devem estar imbuídos da responsabilidade de executar ações educativas e de conscientização para informar a comunidade dos riscos e como proceder no caso de tratamentos alternativos da água. Já a participação da comunidade é de suma importância no monitoramento local dos surtos de diarreias e mudanças nas características organolépticas da água, alertando os agentes fiscalizadores de forma a assegurar a qualidade da água servida (ANA, 2011).

\subsection{Destinação dos resíduos sólidos}

As famílias no geral reciclam a matéria orgânica para alimentação de animais e adubação de pequenas hortas. O restante dos resíduos domésticos (metais, plásticos e papeis) tem uma destinação diferenciada. Nas regiões da Toca Fria, Santo Aleixo e Rio do Colégio a população queima papéis e plásticos em buracos, sendo posteriormente enterrados. Na região do Aracaju quase a totalidade da população destina seus resíduos a coleta pública (Tabela 3). Apesar de existir coleta pública na região do Rio do Colégio a população desconhece a prestação de tal serviço, talvez pelo fato de ter sido implantado a cerca de um ano (informações obtidas com a Secretaria de Desenvolvimento e Meio Ambiente de São Fidélis), necessitando, portanto, de meios de comunicação à população.

Segundo Baird (2002) a incineração apresenta aspectos positivos, como a redução do volume dos resíduos, além de eliminar organismos patogênicos, o principal problema é a poluição atmosférica. Os percentuais atribuídos a esse indicador (Tabela 3) são significativos para as regiões de Toca Fria e Santo Aleixo (14,4\%) e para o Rio do Colégio $(9,8 \%)$. No entanto, ainda não existe um aterro controlado para a destinação desses resíduos sólidos no município e no caso das regiões de Toca Fria e Santo Aleixo nem mesmo o serviço de coleta. Apesar de os valores serem significativos para esse indicador, a população local cuida para que esses resíduos não poluam os recursos naturais, demonstrando assim, práticas mitigatórias nesse quesito (com exceção de uma família na região do Rio do Colégio, composta por sete pessoas que lançam seus resíduos nos arredores da residência).

\subsection{Criação de animais}

O sistema amplamente adotado pelos produtores da microbacia Rio do Colégio foi a de pastagem extensiva, onde o gado se desenvolve solto pelo terreno com pequena intervenção do 
produtor, pela adição de sal e às vezes concentrados. Apesar do pequeno número de produtores (07 Toca Fria e Santo Aleixo, 01 Fazenda Recreio,03Aracaju e 05 Rio do Colégio) e um quantitativo de aninais bastante reduzido, com exceção da Fazenda Recreio, conforme observado na Tabela 2, os percentuais dos valores relativo ao manejo do gado (dessedentação diretamente nos cursos hídricos e criação dos animais em até $10 \mathrm{~m}$ ) foram bastante significativos. As regiões de Toca Fria e Santo Aleixo apresentaram um percentual de 16,9\% para esses indicadores, Aracaju $18 \%$ e Rio do Colégio $11,7 \%$.

Esse método difundido por todo o país apresenta baixos custos de manutenção e mão de obra, baixa produção e rentabilidade. Outro aspecto é a grande pressão sobre o meio ambiente, pois a produção depende diretamente da área disponível, sendo as queimadas e o desmatamento uma estratégia para se aumentar a produção.

Segundo Dias et al. (1999), esse sistema de exploração extensivo causa expressivos impactos ambientais negativos gerado pelo superpastoreio, o que provoca alterações na camada superficial do solo, na diversidade das espécies vegetais e favorece os processos erosivos e consequentemente o assoreamento do leito dos corpos hídricos. Os autores ressaltam que a intensidade dos impactos está relacionada à espécie animal, ao porte e a lotação por unidade de área, além da topografia e do tipo do solo da área.

Segundo Lima e Pioczcovski (2010), para uma produção sustentável os animais não podem ter acesso aos cursos hídricos, sendo a dessedentação restrita a bebedouros adequados a espécie e a idade do animal. A dessedentação dos animais diretamente nos cursos hídricos implica em contaminação microbiológica direta através da saliva e das excretas eliminadas, além de alterar os fatores físico-químicos da água, pela movimentação de sedimentos, tornando-a inapropriada para consumo humano.

O arraste dos dejetos aos cursos hídricos aumenta a DBO da água, o que gera redução do oxigênio dissolvido no meio, altera a temperatura, aumenta a turbidez, promove a eutrofização, conforme observado nos trabalhos de Marcantonio et al. (2007), Simplício et al. (2011), modificando a biodiversidade local, fatos apoiado por Braga et al.(2005).

Palhares (2010) relaciona o impacto econômico gerado pela contaminação dos recursos hídricos. A exposição dos rebanhos a água contaminada deixa os animais mais vulneráveis a doenças, o que gera ônus para a produção, além de interferir na qualidade dos produtos, reduzindo a competitividade de commodities agropecuárias.

Quando de trata da produção leiteira, a água contaminada utilizada para dessedentação ou higienização dos recipientes e das instalações tem contribuído para perdas econômicas, devido à deterioração do produto pelo aumento de bactérias e doenças em animais, como mastites, além de prejuízos na saúde humana ao consumir o produto (PICININ, 2010; OTÊNIO et al., 2010; DIAS et al.,1999).

\subsubsection{Medidas mitigadoras}

Oitenta e sete por cento dos produtores permitem o acesso dos animais aos cursos hídricos para dessedentação.

Capoane e Rheinheimer (2013) salientam a importância de se restringir o acesso de animais aos cursos d'água e nascentes de forma a permitir a recomposição da vegetação ciliar e controle da qualidade da água dos corpos hídricos. Carr e Neary (2008), abordam a necessidade de implantar cercas de retenção na pecuária de forma a reduzir a entrada de nutrientes provenientes dos dejetos animais nos corpos hídricos. Portanto, existe a necessidade de analisar a localização da produção pecuária com objetivo de mitigar os riscos de contaminação hídrica e ambiental (PALHARES, 2010).

Diante dos fatos abordados existe extrema necessidade de substituir o sistema de pastagem extensiva para sistemas mais intensivos, aumentando a produtividade e rentabilidade por área (PALERMO, 2011; PRIMAVESI e PRIMAVESI, 2003), destinando áreas para agricultura ou reflorestamento, utilizadas anteriormente na pecuária. 
Como exemplo a simples adoção de pastagens plantadas em substituição das pastagens nativas dobrou a produtividade pecuária no Brasil, de 0,5 cabeça/ha em 1970 para 1cabeça/ha em 2005 com uma redução de 100 milhões de ha de pastagens naturais em 1970 para 54 milhões em 2006 (IBGE, 2006).

O plantio de pastagens utilizando o Sistema Plantio Direto (SPD) possibilita a manutenção da cobertura do solo, revolvendo-o apenas na linha ou cova da semeadura. Esse processo contribui na redução de erosões, de lixiviamento da matéria orgânica e adubos, aumento da eficiência da adubação, redução de custos para o produtor (AMARAL et al., 2012; GONÇALVES et al. 2007; Bertol et al., 2007).

Outro sistema que pode e deve ser utilizado associado ao SPD é o de pastagens rotacionadas em piquetes, que consiste em dividir a área antes destinada pastagem extensiva em lotes menores de forrageiras (piquetes). Esses lotes são utilizados em sequência possibilitando a rebrota e a recuperação da pastagem onde já fora utilizado. O sistema evita o superpastejo e o subpastejo (PALERMO, 2011), permitindo um crescimento rápido e vigoroso com disponibilidade de alimento durante todo o ano, já que não ocorre o pisoteio do gado nas áreas já utilizadas. Oliveira (2006) e Martha Júnior et al. (2003) abordam a metodologia do dimensionamento dos piquetes e a produtividade por área.

Uma das vantagens do manejo do gado em pastagens rotacionadas em relação às pastagens extensivas é a capacidade de lotação, passando de 0,5 cabeça/ha até 8 cabeças/ha (MARTHA JÚNIOR et al., 2003; PALERMO, 2011). Isso aumenta a produtividade, reduzindo as áreas destinadas a pecuária e as utilizando para fins de reflorestamento ou agricultura.

Gonçalves et al. (2007) apresenta vários modelos de rotação de culturas em piquetes de acordo com a regionalidade, resistência a pragas e interesse econômico.

Amaral et al.(2012), Balbino et al. (2011) e Balbino et al. (2012) descrevem a estratégia Integração Lavoura-Pecuária-Floresta (iLPF) como uma forma de produção sustentável onde as atividades agrícolas, pecuárias e/ou florestais são exercidas em uma mesma unidade de manejo de forma consorciado ou rotacionado. O sistema proporciona melhor aproveitamento do terreno, reduzindo os impactos ambientais da agropecuária.

O sistema iLPF contribui para a recuperação de áreas degradadas, proteção dos recursos hídricos e do solo, reciclagem dos nutrientes de forma eficiente, maiores rendimentos econômicos a menor custo e com qualidade superior, diversificação de oferta, redução de defensivos graças ao controle biológico, redução da erosão, distribuição de renda mais uniforme, dentre outras vantagens (AMARAL et al., 2012; BALBINO et al., 2011 e 2012; KLUTHCOUSKI et al., 2004).

Macedo (2009) trata como promissor o sistema agropastoril ou iLP (integração LavouraPecuária)- uma das modalidades iLPF- associado ao SPD para a recuperação das áreas de pastagens degradadas, inferindo na melhoria das propriedades do solo, proporcionando a produção de forrageiras de melhor qualidade, otimizando a produtividade.

Balbino et al. (2011) salienta que inserir o componente arbóreo ao sistema iLP, representa um avanço inovador, pois permite uma produção diversificada ao longo do ano, como grãos, carne ou leite e produtos madeireiros e não madeireiros. Além disso, o sombreamento fornecido pelas espécies arbóreas, evita perdas na produtividade pecuária como queda na produção de leite e abortamento provocado pelo estresse térmico (OLIVEIRA, 2006).

Ao se adotar o sistema de iLPF, os resíduos deixados pelo gado são rapidamente reciclados e enriquecendo o solo (BALBINO et al., 2011; BALBINO et al., 2012; DIAS et al., 1999).

Com relação as suinoculturas o melhor sistema observado e economicamente viável a produção de subsistência é o de cama sobreposta ou Deep Bedding, onde um material rico em carbono como palha, casca de arroz, maravalha, é colocado dentro das granjas. Desta forma os dejetos se misturam ao substrato, atingindo as proporções ideais de C/N (entre 20:1 e 35:1) e iniciando o processo de compostagem in situ (OLIVEIRA e NUNES, 2002; PALHARES e GEBLER, 2014) .

Dentre os fatores positivos pode-se destacar: a produção de fertilizante de boa qualidade, redução dos maus odores e moscas e principalmente um sistema produtivo que exerce menos 
pressão sobre o ambiente (NUNES, 2003; OLIVEIRA e NUNES, 2002; PALHARES e GEBLER, 2014).

Referente à atividade de piscicultura Dias et al. (1999) e Valenti (2002) recomendam a adoção das seguintes medidas mitigadoras na implantação e operação das atividades de aquicultura, na qual a piscicultura está incluída:

$>$ Escolher locais para a instalação dos tanques escavados, em locais degradados e que não interfiram nos usos da água a montante e a jusante;

> Utilizar os efluentes dos tanques, para outras atividades, como a irrigação de plantações;

$>$ Usar ração de qualidade, evitando sobras que enriqueçam as águas com nutrientes, implicando na necessidade de renovação das águas dos tanques;

$>$ Ao drenar um tanque, direcionar o efluente para um tanque de sedimentação, seguido de filtração mecânica ou remoção dos nutrientes com vegetação aquática;

> Priorizar a produção de espécies nativas e no caso de produção de espécies exóticas, implantar mecanismos que impeçam o escape para o ambiente (uso de telas).

Eler e Millani (2007) salientam a necessidade de fiscalização, obrigando o produtor a requerer a outorga do uso d'água e a adoção de medidas, que não interfiram na qualidade da água ou na biodiversidade local.

\subsection{Supressão da mata ciliar}

Foi detectado que 35\% das residências que utilizam das nascentes para abastecer suas residências não possuíam mata ciliar preservada nas nascentes, além de permitir o acesso de animais. Foi constatado também que existe uma cultura por parte da população local de se desmatar a vegetação ciliar, com o objetivo de permitir o acesso de criações aos cursos hídricos para dessedentação, fato observado também por Dias et al. (1999).

Tal comportamento compromete diretamente a qualidade da água. A erosão por falta da vegetação ripária aumenta a turbidez. O lixiviamento da matéria orgânica depositada ao redor (dejetos animais e humanos) e dos produtos químicos utilizados na agricultura (defensivos e adubo químico), promovem a contaminação físico-química e microbiológica, fazendo com que a depuração da matéria orgânica também seja afetada. Segundo Ragosta et al.(2010) a redução em 1 $\%$ da cobertura vegetal ciliar implica em um aumento de 4,6 NMP/100ml de bactérias do gênero Enterococus nas amostras de água.

\subsubsection{Medidas mitigadoras}

As principais formas de mitigar os impactos relacionados à supressão da vegetação ciliar ou ripária são a recomposição da vegetação nas áreas degradas e preservação das áreas nativas. Neste sentido a legislação tem um papel preponderante na imposição de obrigatoriedade.

Portanto torna-se necessário restringir o acesso de animais aos cursos hídricos com cercas e instalação de caixas de dessedentação e abandonar atividades agropecuárias desenvolvidas nas proximidades, conforme a legislação atual - Lei 12.727/2012 e MP 571/2012 (BRASIL, 2012), incluindo pastagens. Permitindo a regeneração natural da vegetação ripária ou desenvolvimento das espécies implantadas para a recuperação das matas ciliares (CAPOANE e RHEINHEIMER, 2013; PINTO et al., 2005)

Ao se adotar o sistema de iLPF, proposto pelos autores Balbino et al.( 2011), Amaral et al. (2012); Balbino et al. (2011), Balbino et al. (2012), Kluthcouski et al.(2004), irá reduzir as áreas destinadas a produção pecuária, mantendo a mesma produtividade ou superior, não havendo perdas econômicas, permitindo restringir as áreas de APP conforme a legislação, para a recomposição da vegetação ciliar. 


\subsection{Saúde familiar rural}

Foram relatados 20 casos de diarreia (10 em Toca Fria e Santo Aleixo 02 no Aracaju e 08 no Rio do Colégio) e 11 casos de verminoses confirmados por diagnostico médico (conforme moradores) em Toca Fria e Santo Aleixo. Esses indicadores apresentaram um percentual de 14,8\% para as regiões de Santo Aleixo e Toca Fria 1,4\% para o Aracaju e 6,5\% para o Rio do Colégio. Com relação a outras DRSAIs a única relatada foi a dengue com um caso nas regiões da Toca Fria e Santo Aleixo, um caso no Aracaju e seis relatos na região do Rio do Colégio. No entanto, os moradores que relataram o diagnostico de dengue, disseram ter adquirido a enfermidade nas áreas urbanas do município. Esses relatos conferem com os dados alarmantes disponibilizados pela Secretaria de Estado do Rio de Janeiro para os índices da dengue no Norte Fluminense nos anos 2013 e 2014, ( 100 casos registrados em 2013 e 16 em 2014 no município de São Fidélis), tornando as alegações cabíveis. Sendo assim é difícil a comprovação dos casos registrados para a localidade. Tal aspecto positivo se deve, principalmente, pelo manuseio dos resíduos sólidos (conforme já comentado), não permitindo a existência de criadouros para mosquitos como o Aedes aegipty.

Outro fato preocupante observado é com relação à prevenção de verminoses, onde $27,5 \%$ da população das regiões da Toca Fria e Santo Aleixo não fazem uso de vermífugos apesar do alto índice de verminoses constatado. No Aracaju $56,2 \%$ da população não utiliza vermífugos, devido a confiança infundada na qualidade das águas. $\mathrm{Na}$ região do Rio do Colégio onde parte da população tem sido obrigada a utilizar do curso hídrico principal, relatando grande preocupação com a qualidade da água consumida, apenas $13,8 \%$ da população alegou não usar vermífugos a mais de um ano.

Uma pessoa parasitada por Taenia saginata (conhecida popularmente como solitária), adquirida pela ingestão de carne de boi mal cozida elimina cerca de 700.000 ovos por dia, se parasitada por Taenia solium, eliminará cerca de 200.000 ovos por dia, esses ovos são resistentes perdurando por mais de quatro meses no ambiente e resistem a quase todo tratamento da água (REY, 2014). Os ovos da Taenia saginata, ao encontrarem os cursos hídricos poderão infectar o gado que utilize essas águas, reduzindo o valor econômico da carne e contribuindo para a disseminação dessa verminose. No caso da Taenia solium os problemas são ainda mais graves. Se uma pessoa ingerir os ovos seja pela água ou por hortaliças ingeridas cruas, irrigadas com água contaminada, esta tomará o lugar do hospedeiro intermediário (o suíno), produzindo cistos com os vermes em várias partes do corpo, sendo o quadro clínico extremamente grave quando os vermes se instalam no cérebro, essa doença é denominada cisticercose (REY,2014). Com a Ascaridíase não é diferente os ovos são extremamente resistentes podendo permanecer viáveis no ambiente por vários meses a um ano. Ao ingerir água com os ovos ou alimentos ingeridos crus, mal lavados e não desinfetados, irrigados com água contaminada, o homem sendo o único hospedeiro, completa o ciclo da verminose. A quantidade de vermes é o principal risco a vida, podendo obstruir os intestinos (REY, 2014), necessitando de cirurgia urgente e caso não aconteça evolui para óbito.

Cabe ressaltar que os onze casos de verminoses constatados se localizam nas vertentes da microbacia (Toca Fria e Santo Aleixo), onde é comum a prática de laçar o esgoto doméstico nos cursos hídricos ou peridomiciliar e a apenas cerca de $4 \mathrm{Km}$ está localizada a Fazenda Recreio com uma atividade pecuária extensa (cerca de 700 cabeças) e onde o gado utiliza as águas do córrego para dessedentação.

\subsubsection{Medidas mitigadoras}

A saúde ambiental está intimamente ligada à saúde da população e a um estilo de vida sustentável. Apesar dessa premissa, muitas vezes a saúde ambiental tem sido negligenciada, devido à ausência de comunicação entre vários setores (CAIRNCROSS et al., 2003).

Ao implantar as medidas mitigatórias relacionadas ao saneamento das regiões da microbacia Rio do Colégio (conforme já abordado nos itens anteriores), resultará em benefícios diretos na 
saúde da população local. Segundo Heller (1997) a intervenção nas áreas do saneamento, refletem de forma positiva na saúde da população.

O manejo adequado na agropecuária e a preservação das matas ciliares dos cursos hídricos foram discutidos nos itens anteriores. A adoção de tais medidas preservam os recursos naturais, melhorando a produtividade agropecuária, reduz as morbidades e os gastos hospitalares e com medicamentos. Desta forma, proporcionando aumento de renda, do IDH e redução dos gastos públicos com a saúde.

No entanto, existe a necessidade de políticas públicas para a implantação de projetos mitigadores, fiscalização, estudos epidemiológicos, divulgação de informações, entre outras ações, que visem a preservação ambiental para a promoção da saúde (Heller, 1997; CAIRNCROSS et al., 2003; FUNASA, 2002; BRASIL, 2009).

\subsection{Análise microbiológica da água}

A análise microbiológica apresentou coliformes termotolerantes em todas as amostras indicando a contaminação fecal de origem humana e/ou animal (Figura 4). Na coleta realizada no período de estiagem a concentração de coliformes se mostrou significativamente mais baixa que a realizada no período chuvoso, com exceção do ponto 1 . Tais diferenças estão relacionadas à sazonalidade, onde em períodos de alta pluviosidade ocorre o arraste da matéria orgânica fecal depositada nas proximidades dos cursos hídricos, elevando a concentração dos coliformes fecais. Amaral (2003) concluiu que existe uma relação direta entre a presença dos coliformes fecais com os períodos chuvosos, exatamente devido ao arraste de matéria fecal. O resultado microbiológico concorda com a pesquisa de campo onde foi encontrado um número elevado de residências com esgotamento a céu aberto (peridomiciliar ou diretamente nos cursos hídricos), ausência de cobertura vegetal e a criação extensiva de gado nas proximidades dos corpos hídricos, não deixando duvidas sobre a origem dos coliformes fecais detectados.

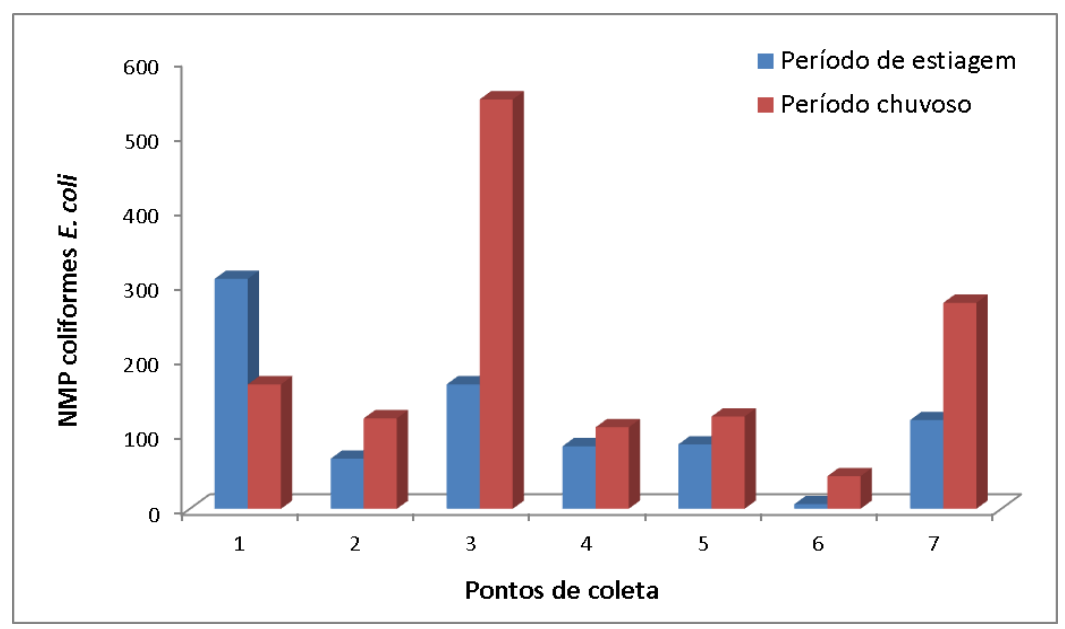

Figura 4 - Resultado microbiológico para coliformes termotolerantes (NMP) nos 7 pontos amostrados das regiões analisadas da microbacia Rio do Colégio.

As contaminações microbiológicas encontradas no Ponto 1, provavelmente estão relacionadas com a forma de esgotamento sanitário nas regiões da Toca Fria e Santo Aleixo. Os Pontos 2 e 3 não deixa duvidas da origem da contaminação microbiológica, ao apresentar um aumento de E. coli de cerca de $400 \%$ ao percorrer a região da Fazenda do Recreio com a extensa atividade pecuária. Na região do Aracaju entre os Pontos 4 e 5, observamos que as medidas mitigadoras mínimas já utilizadas pela população, mantiveram os índices de $E$. coli sem alterações, corroborando com a significância dos impactos para a região, obtido pela matriz de impacto 8,6, classificado como pouco significativo. Entre os Pontos 6 e 7 está a região do Rio do Colégio, o aumento nas 
concentrações de E. coli provavelmente está relacionada a instalação inadequada das fossas rústicas e a falta de manejo na pecuária.

A resolução do CONAMA n⿳0357/2005 classifica as águas de acordo com seus usos, estabelecendo limites máximos para aproximadamente 100 parâmetros para as cinco classes estipuladas (BRAGA et al., 2005). O parâmetro microbiológico para coliformes fecais da região, indica que houve modificação na classificação da primeira amostragem ( na estiagem) em relação a segunda ( período chuvoso). Nos pontos 3 e 7 os valores deixaram de enquadrar na classe 1 (até 200 coliformes termotolerantes), passando para classe 2 (até 1000 coliformes termotolerantes). Esta mudança de classe tornam essas águas inviáveis para consumo humano por tratamento simplificado, necessitando de tratamento convencional, além restringir a irrigação de hortaliças ingeridas cruas e de frutas que se desenvolvam rentes ao solo e que sejam ingeridas cruas sem remoção de película (CONAMA, 357/05 Art. 4 parágrafos II e III).

Palhares e Gebler (2014) apontam o esterco animal como contaminante microbiológico comum nos recursos hídricos, proveniente da excreção direta nos corpos hídricos, da lixiviação das excretas ou da própria adubação. Isso contribui para surtos de diarreias, infecções intestinais e urinarias em humanos e mastites no gado, causada por algumas espécies de coliformes como E. coli, E. aerogenes, Klebsiella, entre outras.

\section{Conclusão}

Os principais impactos caracterizados foram concernentes à forma de esgotamento sanitário, o manejo da pecuária no sistema extensivo de produção, degradação da vegetação ciliar das nascentes e constatação de doenças relacionadas ao saneamento inadequado (DRSAI).

A prática de defecação a céu aberto ou esgotamento peridomiciliar ou diretamente nos afluentes do Rio do Colégio, observada principalmente pela população localizada a montante, nas regiões da Toca Fria e Santo Aleixo, gera um potencial risco de disseminações de doenças causadas por vírus, bactéria, protozoários, fungos e helmintos.

O sistema de produção pecuária observado em todas as regiões da microbacia foi o sistema extensivo, que altera a qualidade microbiológica da água, constatada principalmente nas coletas do período chuvoso, com aumento dos coliformes E. coli, em quase todos os pontos, sendo o ponto 3 (Fazenda Recreio) crucial nessa argumentação.

O reflexo dos impactos ambientais sobre a saúde da população local ficou evidente nos altos índices de diarreias e verminoses constatados. Tal fato justifica a necessidade de se implantar de medidas mitigadoras, viáveis a realidade local, para sanar as contaminações sanitárias humanas e disposição inadequada de dejetos animais, mantendo a quantidade do recurso e melhorando a sua qualidade.

A matriz de impacto elaborada se mostrou eficiente em apontar regiões potencialmente impactantes, além de especificar os impactos prioritários para cada região, sendo, portanto uma excelente ferramenta para os gestores ambientais e órgãos públicos.

\section{Agradecimentos}

À Secretaria de Desenvolvimento e Meio Ambiente (SEMDA) de São Fidélis, pelo suporte no deslocamento pela microbacia e na presteza nas informações solicitadas; À Unidade de Pesquisa e Extensão Agro-Ambiental do Instituto Federal Fluminense (UPEA-IFF) pelas análises microbiológicas; Ao Instituto Estadual do Ambiente do Parque Estadual do Desengano (INEAPED), por acompanhar o projeto de pesquisa, fornecer transporte e pessoal para a coleta de água no período chuvoso. 


\section{Referências}

AMARAL, Denise Deckers; CORDEIRO, Luiz Adriano Maia; GALERANI, Paulo Roberto. Plano Setorial de Mitigação e Adaptação às Mudanças Climáticas para Consolidação da Economia de Baixa Emissão de Carbono na Agricultura-PLANO ABC (Sectoral Plan for Mitigation and Adaptation to Climate Change for a Consolidation Economy Low Carbon...). Revista Brasileira de Geografia Física, v. 4, n. 6, p. 1266-1274, 2012. Disponível em: < http://www.agricultura.gov.br/arq editor/download.pdf $>$. Acesso em 20 de jul. de 2015.

AMARAL, Luiz Augusto do et al . Água de consumo humano como fator de risco à saúde em propriedades rurais. Rev. Saúde Pública, São Paulo, v. 37, n. 4, p. 510-514, aug. 2003. Disponível em: $<$ http://www.scielo.br/scielo.php?script=sci arttext\&pid=S003489102003000400017\&lng=en\&nrm=iso $>$. Acesso em 15 de Abril de 2015. http://dx.doi.org/10.1590/S0034-89102003000400017.

ANA (AGÊNCIA NACIONAL DE ÁGUAS). Cuidando das Águas: soluções para melhorar a qualidade dos recursos hídricos. Programa das Nações Unidas para o Meio Ambiente. Brasília: ANA, $2011 . \quad$ Disponível em: <http://www.pnuma.org.br/admin/publicacoes/texto/Cuidando das aguas final baixa.pdf $>$. Acesso em 15 de Dezembro de 2014.

ASSOCIAÇÃO BRASILEIRA DE NORMAS TÉCNICAS. NBR 7229: Projeto, construção e operação de sistemas de tanques sépticos. Rio de Janeiro: ABNT-Associação Brasileira de Normas Técnicas, 1993.

BAIRD, C. Química Ambiental. 2 ed. Porto Alegre: Bookman, 2002.

BALBINO, Luiz Carlos et al. Evolução tecnológica e arranjos produtivos de sistemas de integração lavoura-pecuária-floresta no Brasil. Pesquisa Agropecuária Brasileira, v. 46, n. 10, p. 0-0, 2011. Disponível em: < http://www.scielo.br/scielo.php?pid=S0100-

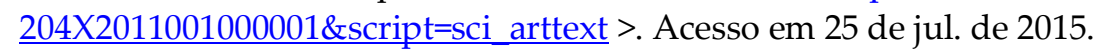

BALBINO, Luiz Carlos; CORDEIRO, Luiz Adriano Maia; DE OLIVEIRA, Priscila. Agricultura sustentável por meio da integração lavoura-pecuária-floresta (iLPF). Informações Agronômicas, n. 138, p. 1-18, 2012. Disponível em: < http://www.ipni.net/PUBLICATION/IABRASIL.NSF/0/67E9CCA96D48CF6685257A84004F5D7D/\$FILE/IA-2012-138.pdf >. Acesso 25 de jul. de 2015.

BERTOL, Oromar João et al. Perdas de solo e água e qualidade do escoamento superficial associadas à erosão entre sulcos em área cultivada sob semeadura direta e submetida às adubações mineral e orgânica. Revista Brasileira de Ciência do Solo, v. 31, n. 04, p. 781-792, 2007. Disponível em: <http://www.scielo.br/pdf/rbcs/v31n4/a18v31n4.pdf $>$. Acesso em 26 de jul. de 2015.

BOCKSTALLER, Christian et al. Agri-environmental indicators to assess cropping and farming systems: a review. In: Sustainable Agriculture. Springer Netherlands, 2009. p. 725-738. Disponível em: < http://link.springer.com/chapter/10.1007/978-90-481-2666-8 44\#page-1 >. Acesso em 05 de jul. de 2014.

BRAGA, B. et al. Introdução à Engenharia Ambiental. $2^{\circ}$ ed. São Paulo: Pearson Prentice Hall. 2005.

BRASIL. Ministério da Saúde. Secretaria de Vigilância em Saúde. Departamento de Análise de Situação de Saúde. Saúde Brasil 2008 : 20 anos de Sistema Único de Saúde (SUS) no Brasil. Brasília : Ministério da Saúde, 2009. 416 p. : il. Disponível em: < https://www.google.com.br/?gws rd=ssl\#q=ISBN+978-85-334-1600-0 $>$. Acesso em $20 \mathrm{de}$ fev. de 2015. 
BRASIL. Portaria n. ${ }^{\mathbf{5}}$ 518, de 25 de março de 2004. Normas e padrões de potabilidade das águas destinadas ao consumo humano. Brasília (DF): MS, 2004. Disponível em:

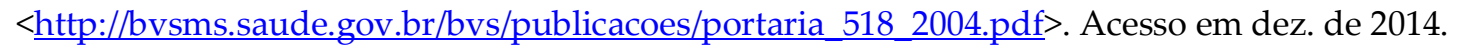

CAIRNCROSS, Sandy et al. Health, environment and the burden of disease; a guidance note. DFID, 2003. Disponível em: < http://www.bvsde.paho.org/bvsapc/fulltext/cairn.pdf $>$. Acesso em 01 de set. de 2015.

CAPOANE, V.; RHEINHEIMER, D. S. Usos antrópicos em áreas de preservação permanente: estudo de caso em um assentamento de reforma agrária. Extensão Rural (Santa Maria), v. 20, p. 7-23,

Disponível em:<http://oaji.net/articles/2014/1572-1420655477.pdf $>$. Acesso em 27 de jul. de 2015.

CARR, Genevieve M.; NEARY, James P. Water quality for ecosystem and human health. UNEP/Earthprint, $2008 . \quad$ Disponível em: http://www.unwater.org/wwd10/downloads/water quality human health.pdf. Acesso em 15 de dez. de 2014.

CONAMA. Conselho Nacional do Meio Ambiente. Resolução nº 357, de 17 de Março de 2005. Dispõe sobre a Legislação Ambiental brasileira. 2005. Disponível em: <http://www.mma.gov.br/port/conama/res/res05/res35705.pdf / >. Acesso em: 28 de jul. 2014.

CONAMA. Conselho Nacional do Meio Ambiente. Resolução no 01, de 23 de Janeiro de 1986. Dispõe sobre critérios básicos e diretrizes gerais para o Relatório de Impacto Ambiental RIMA. 1986. Disponível em: <http://www.mma.gov.br/port/conama/res/res86/res0186.html >. Acesso em: 30 de jul. de 2014.

DIAS , M. C. et al. Manual de impactos ambientais: orientações básicas sobre aspectos ambientais de atividades produtivas. Fortaleza: Banco do Nordeste, 1999. 297p. Disponível em: $<$ http://www.mma.gov.br/estruturas/sqa_pnla/_arquivos/manual_bnb.pdf $>$. Acesso em 22 de jun. de 2015.

ELER, Márcia Noélia; MILLANI, Thiago José. Métodos de estudos de sustentabilidade aplicados a aquicultura. Revista Brasileira de Zootecnia, v. 36, p. 33-44, 2007. Disponível em: < http://www.scielo.br/pdf/rbz/v36s0/04.pdf >. Acesso em 28 de ago. de 2015.

FUNASA. Fundação Nacional de Saúde. Impactos na Saúde e no Sistema Único de Saúde Decorrentes de Agravos Relacionados a um Saneamento Ambiental Inadequado / Fundação Nacional de Saúde - Brasília: Fundação Nacional de Saúde, 2010. Disponível em: $<$ http://www.funasa.gov.br/site/wp-content/files mf/estudosPesquisas ImpactosSaude.pdf $>$. Acesso em: 20 de fev. de 2014.

FUNASA. Fundação Nacional de Saúde. Vigilância ambiental em saúde. Brasília: Fundação Nacional de Saúde, 2002. 42 p. Disponível em: < http://bvsms.saude.gov.br/bvs/publicacoes/manual sinvas.pdf $>$. Acesso em: 20 de fev. de 2014.

GLASSON, John; THERIVEL, Riki; CHADWICK, Andrew. Introduction to environmental impact assessment. Routledge, 4th ed. 2012.

GONÇALVES, S. L. et al. Rotação de cultura. Comunicado técnico/Embrapa Pecuária Sudeste, 45, 2007. Disponível em: < https://www.embrapa.br/ > . Acesso em 20 de jul. de 2015.

GRACIOLI, Cibele Rosa. Impactos ambientais na microbacia do rio Vacacaí-Mirim em Santa Maria-RS. 2005. Disponível em: <http://www.bibliotecaflorestal.ufv.br/handle/123456789/5014 >. Acesso em 20 de ago. de 2015.

HEINK, Ulrich; KOWARIK, Ingo. What are indicators? On the definition of indicators in ecology and environmental planning. Ecological Indicators, v. 10, n. 3, p. 584-593, 2010. Disponível em: $<$ http://mon.univmontp2.fr/claroline/backends/download.php?url=L2FydGljbGVzIHBvdXIgZX 
R1ZGlhbnRzL0xFIENBRFJFIEVOVDIucGRm\&cidReset=true\&cidReq=FMOE302 > . Acesso em: 29 mar. de 2015.

HELLER, Leo. Saneamento e Saúde. Brasília: OPAS, 1997.

HELLER, Léo; PÁDUA, Valter Lúcio. Abastecimento de água para consumo humano. Editora UFMG, 2006.

IBGE. Instituto Brasileiro de Geografia e Estatística. Censo Agropecuário: 2006. Rio de Janeiro: Instituto Brasileiro de Geografia e Estatística. Disponível em: < www.ibge.gov.br.>. Acesso em 20 de jul. de 2015.

IBGE. Instituto Brasileiro de Geografia e Estatística. Pesquisa Nacional de Saneamento Básico, $2008 . \quad$ Disponível em: $<$ http://www.ibge.gov.br/home/estatistica/populacao/condicaodevida/pnsb2008/PNSB_2008.pdf >. Acesso em: 17 dez. de 2014.

ICMM - International Council on Mining and Metals. Good practice guidance on health impact assessment. London: ICMM, 2010. Disponível em: $<$ https://www.icmm.com/document/792 > . Acesso em 05 de jun. de 2015.

JORDÃO E. P. e PESSOA, C. A. Tratamento de Esgotos Domésticos. 5ª ed. Rio de Janeiro, 2009.

KLUTHCOUSKI, João et al. Integração lavoura-pecuária e $\mathbf{o}$ manejo de plantas daninhas. Informações agronômicas, n. 106, p. 1-20, 2004. Disponível em: $<$ http://www.ipni.net/publication/ia-

brasil.nsf/0/6C803EB334A9440E83257AA2005A8E45/\$FILE/Encarte106.pdf $>$. Acesso em 25 de jul. de 2015.

LEOPOLD, L.B, CLARK,F.F, HANSHAW,B.B, BALSLEY,J.R. A procedure for evaluating environmental impact, US Geological Survey Circular 645. Department of the Interior, Washington, DC, USA, 1971. Disponível em: $<$ http://eps.berkeley.edu/people/lunaleopold/(118)\%20A\%20Procedure $\% 20$ for $\% 20$ Evaluating $\% 2$ 0Environmental\%20Impact.pdf > . Acesso em 20 de jan. de 2015.

LIMA, Gustavo J. M. M.; PIOCZCOVSKI, Guilherme D. de. Água: principal alimento na produção animal. Simpósio Produção Animal e Recursos Hídricos, 2010. Disponível em: $<$ http://www.cnpsa.embrapa.br/sgc/sgc publicacoes/publicacao e1u76v6p.pdf\#page=29> Acesso em 05 de jan. de 2015.

MACEDO, M.C.M. Integração lavoura e pecuária: o estado da arte e inovações tecnológicas. Revista Brasileira de Zootecnia, v.38, p.133-146, 2009. Disponivel em: < http://www.scielo.br/pdf/rbz/v38nspe/v38nspea15.pdf >. Acesso em 25 de jul. de 2015.

MARTHA JÚNIOR, G. B. et al. Área de piquete e taxa de lotação no pastejo rotacionado. Embrapa Cerrados. Comunicado Técnico 101, 2003.

NUNES, M. L. A. Avaliação de procedimentos operacionais na compostagem de dejetos de suínos. 2003. 117 f. Dissertação (Mestrado em Engenharia Ambiental) - Programa de PósGraduação em Engenharia Ambiental, Universidade Federal de Santa Catarina, Santa Catarina. Disponível em: < https://repositorio.ufsc.br/handle/123456789/85966 > . Acesso em 20 de ago. de 2015.

OLIVEIRA, P. P. A. Dimensionamento de piquetes para bovinos leiteiros, em sistemas de pastejo rotacionado. Comunicado técnico/Embrapa Pecuária Sudeste; 65, 2006. Disponível em: < https://www.embrapa.br/ >. Acesso em 02 de ago. de 2015.

OLIVEIRA, P.A. V.; NUNES, M. L. A. Sustentabilidade ambiental da suinocultura. 2002. Disponível em: < http://www.ufvjm.edu.br/disciplinas/agr006/files/2014/08/Sustentabilidadeambiental-da-suinocultura-EMBRAPA.pdf >. Acesso em 25 de ago. de 2015. 
OMS/UNICEF (2014) Progress on Drinking Water and Sanitation, 2014 update ["Progresso relativamente a Água Potável e Saneamento, actualização de 2014"]. Disponível em: < www.who.int/water sanitation health/publications/2014/jmp-report/en/> Acesso em 12 de dez. de 2014

OTÊNIO, Marcelo Henrique et al. Cloração de Água para Propriedades Rurais. EMBRAPA, 2010. Disponível em: $<\quad$ https://www.embrapa.br/gado-de-leite/busca-de-publicacoes//publicacao/875235/cloracao-de-agua-para-propriedades-rurais >. Acesso em 20 de jun. de 2015.

PALERMO, Giuseppe Cernicchiaro. Emissões de gases de efeito estufa (GEE) e medidas mitigatórias da pecuária: potencialidades da intensificação e do confinamento do gado bovino de corte brasileiro. 2011. Tese de Doutorado. Universidade Federal do Rio de Janeiro. Disponível em: < http://www.ppe.ufri.br/ppe/production/tesis/giuseppe palermo.pdf $>$. Acesso em 21 de Julho de 2015.

PALHARES, Julio Cesar Pascale. Quantidade e qualidade da água na produção de suínos. Simpósio Produção Animal e Recursos Hídricos, p. 33, 2010. Disponível em: <http://www.cnpsa.embrapa.br/sgc/sgc publicacoes/publicacao e1u76v6p.pdf\#page=29> Acesso em 05 de jan. de 2015.

PALHARES, Julio Cesar Pascale; GEBLER, Luciano. Gestão ambiental na agropecuária. v.2 Brasília, DF: Embrapa, 2014. 490p.

PICININ, Lídia Cristina Almeida. Quantidade e qualidade da água na produção de bovinos de leite. Simpósio Produção Animal e Recursos Hídricos, p. 33, 2010. Disponível em: < http://www.cnpsa.embrapa.br/sgc/sgc publicacoes/publicacao e1u76v6p.pdf\#page=29 $\quad>$. Acesso em 05 de jan. de 2015.

PINTO, Lilian Vilela Andrade et al . Estudo da vegetação como subsídios para propostas de recuperação das nascentes da bacia hidrográfica do ribeirão Santa Cruz, Lavras, MG. Rev. Árvore, Viçosa , v. 29, n. 5, p. 775-793, out. 2005 . Disponível em: < http://www.scielo.br/scielo.php?script=sci arttext\&pid=S010067622005000500013\&lng=pt\&nrm=iso $>$. Acessos em 06 de ago. 2015.

PINTO, Lilian Vilela Andrade; ROMA, T. N.; BALIEIRO, KRC. Avaliação qualitativa da água de nascentes com diferentes usos do solo em seu entorno. Cerne, v. 18, n. 3, p. 495-505, 2012. Disponível em: $<$ http://www.scielo.br/pdf/cerne/v18n3/a18v18n3.pdf $>$. Acesso em 30 de jul. de 2015.

PRIMAVESI, A. C.; PRIMAVESI, O. Criação de bovinos de corte na região sudeste. Criação de Bovinos de Corte na Região Sudeste, 2003. Disponível em: < http://sistemasdeproducao.cnptia.embrapa.br/FontesHTML/BovinoCorte/BovinoCorteRegiaoSu deste/producaocarne.htm >. Acesso em 05 de jul. de 2015.

PRÜSS-ÜSTÜN A., R. Bos, F. Gore, and J. Bartram. (2008). Safer water, better health: costs, benefits and sustainability of interventions to protect and promote health. World Health Organization, Geneva, 2008. Disponível em: $<$ http://whqlibdoc.who.int/publications/2008/9789241596435 eng.pdf $>$. Acesso em 10 de dez. de 2014.

RAGOSTA G, E. C.; ATWILL E.R.; WALKER M.; TICKTIN T.; ASQUITH A.; TATE K.W. Causal connections between water quality and land use in a rural tropical island watershed. Ecohealth, 7(1), pp. 105-113, 2010. Disponível em:< http://www.ncbi.nlm.nih.gov/pmc/articles/PMC2914289/>. Acesso em 07 de dez. de 2014.

REY, L. Bases da parasitologia médica. 3eed [Reimpr.]. Rio de Janeiro. Guanabara Koogan, 2014.

RODRIGUES, Geraldo Stachetti; CAMPANHOLA, Clayton. Sistema integrado de avaliação de impacto ambiental aplicado a atividades do Novo Rural. Pesquisa Agropecuária Brasileira, v. 
38, n. 4, p. 445-451, 2003. Disponível em: < http://www.scielo.br/pdf/pab/v38n4/a01v38n4.pdf $>$. Acesso em: 29 de Janeiro de 2015.

SANCHÉS, L.E. Avaliação de Impacto Ambiental - Conceitos e Métodos. 2ª ed. São Paulo: Oficina de Textos, 2013.

SIMPLÍCIO, Nathan de Castro Soares et al. Avaliação da qualidade da água superficial em áreas de bovinocultura no cerrado. In: Simpósio Brasileiro de Recursos Hídricos, 19. Maceió, 2011. Associação Brasileira de Recursos Hídricos, 2011. Disponível em: <https://www.abrh.org.br/sgcv3/UserFiles/Sumarios/62959578617aa9f48dc9361f4f91265b 5db97 7b4763c1a6188c6d266d91fb07d.pdf>. Acesso em 07 de dez. de 2014.

VALENTI, W. C. Aqüicultura sustentável. In: Congresso de Zootecnia, Vila Real, Portugal, Proceedings of the Associação Portuguesa dos Engenheiros Zootécnicos, [Internet]. 2002. p. 11118.

Disponível

em: $<$ http://www.caunesp.unesp.br/publicacoes/artigos/valenti/CPIL VALENTI Aquicultura\%20su stentavel.pdf $>$. Acesso em 25 de ago. de 2015. 